\title{
SUPERPLASTICITY IN ULTRAFINE-GRAINED MATERIALS
}

\author{
Megumi Kawasaki' and Terence G. Langdon ${ }^{2}$ \\ 'School of Mechanical, Industrial and Manufacturing Engineering, Oregon State University, Corvallis, \\ OR 97331-6001, U.S.A. \\ ${ }^{2}$ Materials Research Group, Department of Mechanical Engineering, University of Southampton, \\ Southampton SO17 1BJ, U.K.
}

Received: June 18, 2018

\begin{abstract}
Superplasticity refers to the ability of a polycrystalline solid to exhibit a high elongation, of at least $400 \%$ or more, when testing in tension. The basic characteristics of superplastic flow are now understood and a theoretical model is available to describe the flow process both in conventional superplastic materials where the grain sizes are a few micrometers and in ultrafinegrained materials processed by severe plastic deformation where the grain sizes are in the submicrometer range. This report describes the basic characteristics of superplastic metals, gives examples of flow in ultrafine-grained materials, demonstrates the use of deformation mechanism mapping for providing a visual display of the flow processes and provides a direct comparison with the conventional model for superplastic flow. The report also describes the potential for using nanoindentation to obtain detailed information on the flow properties using only exceptionally small samples.
\end{abstract}

\section{INTRODUCTION}

When polycrystalline solids are pulled in tension, they generally exhibit necking and then they fail at relatively low elongations. Under some special circumstances, however, it is possible to achieve remarkably high elongations without the occurrence of any significant necking within the gauge lengths. This process is known as "superplasticity" where this is a direct translation of the Russian word sverkhplastichnostmeaning "ultrahigh plasticity" [1]. The first direct demonstration of true superplastic flow was in research conducted by Pearson in England in 1934 [2]. Using a bismuth-tin eutectic alloy, Pearson obtained an exceptional elongation of $1950 \%$ which was far in excess of any other elongations reported in any metals up to that time. Thereafter, significant research was conducted in the Soviet Union to more fully investigate this phenomenon and in 1962 a comprehensive review of this Russian work, published in the United States by Underwood [3], drew world-wide attention to the unusual properties of superplastic materials. A few years later it became clear that superplastic alloys provided a potential for forming smooth and complex shapes from sheet metals [4] and this was the significant step that initiated the process of superplastic forming as a viable manufacturing tool. As of today, superplastic forming is now established as a valuable processing procedure that is used extensively to fabricate complex parts in a range of industrial applications in the aerospace, automotive and architectural sectors as well as making simple parts, such as boxes and panels, for a range of household products [5].

In the early stages of superplasticity, research was undertaken to determine the dependence of superplastic flow on a range of fundamental testing parameters such as temperature and grain size. This work led to a basic understanding of the flow characteristics and especially the ranges of testing conditions associated with the ability to achieve high

Corresponding author: M. Kawasaki, e-mail: megumi.kawasaki@oregonstate.edu 


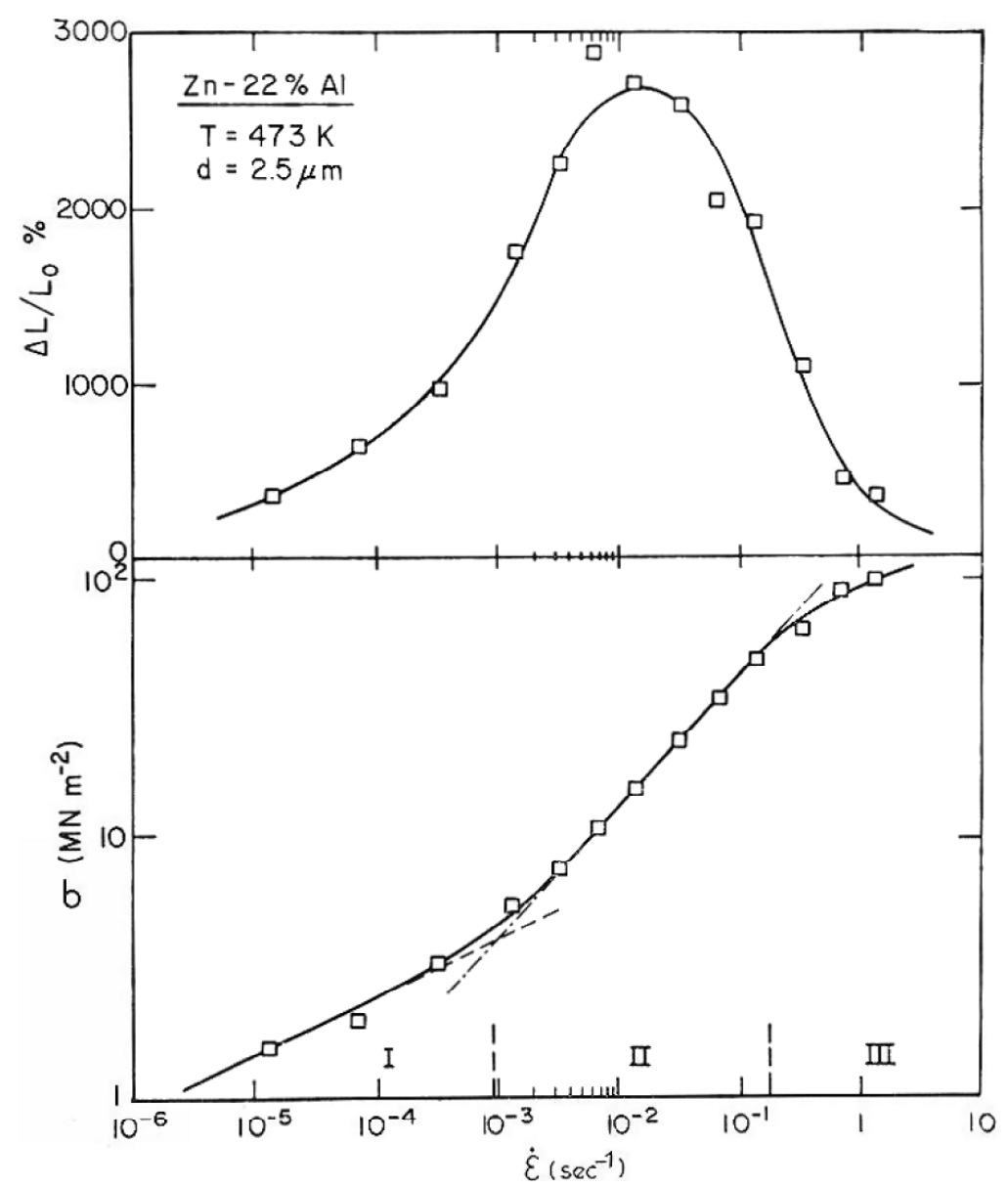

Fig. 1. Elongation to failure (upper) and flow stress (lower) versus initial strain rate for a $\mathrm{Zn}-22 \% \mathrm{Al}$ eutectoid alloy having an average spatial grain size of $2.5 \mu \mathrm{m}$ pulled in tension at a testing temperatures of $473 \mathrm{~K}$ [6].

superplastic elongations. For example, an initial first step entailed testing a $\mathrm{Zn}-22 \% \mathrm{Al}$ eutectoid alloy, selected as a representative two-phase superplastic material with a grain size, $d$, of $2.5 \mu \mathrm{m}$, and determining the variation of elongation over a wide range of strain rates when testing all of the samples at a temperature of $473 \mathrm{~K}$. The results are shown in Fig. 1 where the upper plot gives the various elongations recorded for each sample as a function of the strain rate, $\dot{\varepsilon}$, and the lower plot shows the maximum recorded flow stress, $\sigma$, for each testing condition, where the elongation is denoted as $\Delta L /$ $L_{0} \%$ where $\Delta L$ is the change in length and $L_{0}$ is the initial gauge length, respectively [6]. These results show that the flow behavior divides into three distinct regions, marked regions I, II and III, where superplasticity occurs in region II at intermediate strain rates over a range of about two orders of magnitude in strain rate and the elongations are much lower, and outside of the superplastic range, at both low strain rates in region I and high strain rates in region III. It is now known from many more recent experiments that this type of three-stage flow behavior is representative of a wide range, if not all, superplastic metals. It is important to note also that the strain rate sensitivity, $m$, defined as $\partial \ln \sigma / \partial \ln \dot{\varepsilon}$, is high and $\sim 0.5$ in region II whereas the values of $m$ are much lower and only $\sim 0.2$ in regions I and III.

The elongations for the $\mathrm{Zn}-22 \% \mathrm{Al}$ alloy in Fig. 1 are high and reach maximum values in region II of $>2000 \%$. Even higher superplastic elongations may be recorded in other superplastic alloys: for example, a maximum elongation of $7550 \%$ was recorded in a $\mathrm{Pb}-62 \% \mathrm{Sn}$ eutectic alloy tested at a temperature of $413 \mathrm{~K}$ [7]. In order to provide a clear definition of the elongation required for true superplastic flow, and especially to avoid confusion with the relatively high elongations of $>100 \%$ that may occur when dislocation glide is the rate-controlling flow process with $m \approx 0.3$, the advent of superplasticity is now defined as elongations to failure of at least $400 \%$ [8].

The basic characteristics and the requirements for superplastic flow are now well established [9]. Specifically, superplasticity requires a very small grain size, typically smaller than $\sim 10 \mu \mathrm{m}$, and a 
(a) $d>\lambda$

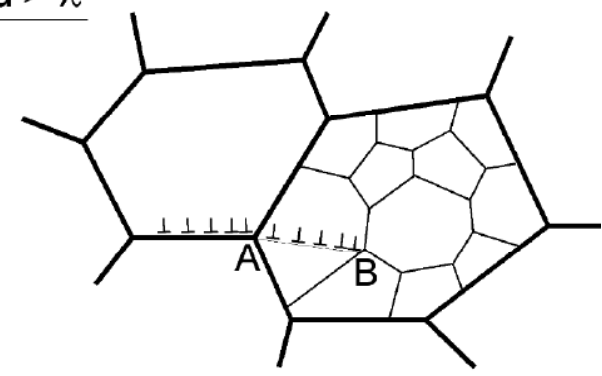

(b) $d<\lambda$

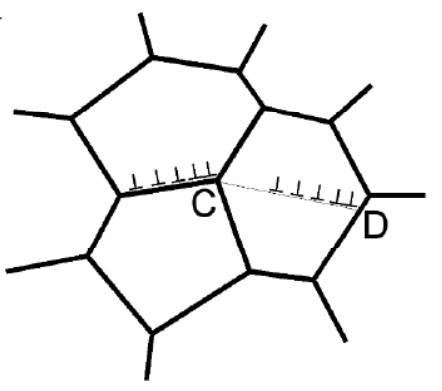

Fig. 2. Schematic illustration of a unified model for grain boundary sliding in (a) conventional creep when $d>\lambda$ and (b) superplasticity when $d<\lambda$ [15].

high testing temperature, typically higher than $\sim 0.5$ $T_{\mathrm{m}}$ where $T_{\mathrm{m}}$ is the absolute melting temperature of the material. Under true superplastic conditions, the samples elongate by several hundreds or even thousands of percent but the grains within the materials remain reasonably equiaxed. This microstructural observation provides a clear demonstration that grain boundary sliding (GBS) is the dominant flow mechanism in superplasticity [10]. Furthermore, several sets of detailed experiments have shown that the sliding in superplasticity is accommodated concurrently by the occurrence of intragranular dislocation slip within the grains but this slip makes no significant contribution to the overall strain [11-13].

Using this information, it is possible to develop a theoretical model for superplasticity and also to provide a clear distinction between the GBS occurring in superplastic flow and the GBS which is an inherent feature of conventional high temperature creep in coarse-grained materials. These two processes are illustrated in Fig. 2. In high temperature creep with coarse-grained samples, the grains become divided into arrays of subgrains having an average size of $\lambda$ so that Fig. 2a corresponds to the condition where $d>\lambda$. Thus, in high temperature creep GBS occurs through the movement of dislocations along the boundaries and this produces stress concentrations as at the triple point A, accommodating slip is initiated in the adjacent grain and these dislocations then move to the first subgrain boundary at $B$ where they climb into the boundary. Conversely, superplasticity requires a small grain size and it has been shown that it needs a grain size which is no larger than the average subgrain size so that $d<\lambda[14]$ as in Fig. 2b. The stress concentration at triple point $C$ due to GBS is then accommodated by intragranular slip in the adjacent grain and now, in the absence of any subgrain boundaries, the dislocations move across the grain and climb into the opposing grain boundary at $D$.

Both of these processes may be expressed by a rate equation of the following form:

$\dot{\varepsilon}=\frac{A D G \mathbf{b}}{k T}\left(\frac{\mathbf{b}}{d}\right)^{p}\left(\frac{\sigma}{G}\right)^{n}$,

where $D$ is the appropriate diffusion coefficient which is given by $D_{0} \exp (-Q / R T)$ where $D_{0}$ is a frequency factor, $Q$ is the activation energy, $R$ is the gas constant and $T$ is the absolute temperature, $G$ is the shear modulus, $\mathbf{b}$ is the Burgers vector, $k$ is Boltzmann's constant, $p$ and $n$ are the exponents of the inverse grain size and the stress, respectively, where $n=1 / m$ and $A$ is a dimensionless constant. It can be shown that the rate of GBS in conventional creep with $d>\lambda$ is given by Eq. (1) with $Q \approx Q$ where $Q_{1}$ is the activation energy for lattice diffusion, $n=3, p=1$, and $A \approx 10^{3}$ whereas the rate of GBS in superplasticity with $d<\lambda$ is also given by Eq. (1) but with $Q=Q_{\mathrm{gb}}$ where $Q_{\mathrm{gb}}$ is the activation energy for grain boundary diffusion, $n=2, p=2$, and $A \approx 10$ [15]. The validity of Eq. (1) in describing superplasticity in ultrafine-grained metals is examined later in Section 3.

\section{SUPERPLASTIC FLOW IN REPRESENTATIVE ULTRAFINE-GRAINED (UFG) METALS}

As noted in Section 1, the dominant flow mechanism for superplasticity by GBS requires a grain size that is smaller than the equilibrium subgrain size, $\lambda$ [14]. The processing of metals through the application of severe plastic deformation (SPD) provides an opportunity for achieving excellent superplastic properties in ultrafine-grained (UFG) metals having high fractions of high-angle boundaries. Numerous experimental reports are available to date and it has been shown that high fractions of high-angle grain boundaries may be achieved after the accumulation of a large strain of at least $\sim 6-8$ in materials processed by equal-channel angular pressing (ECAP) through large numbers of passes 

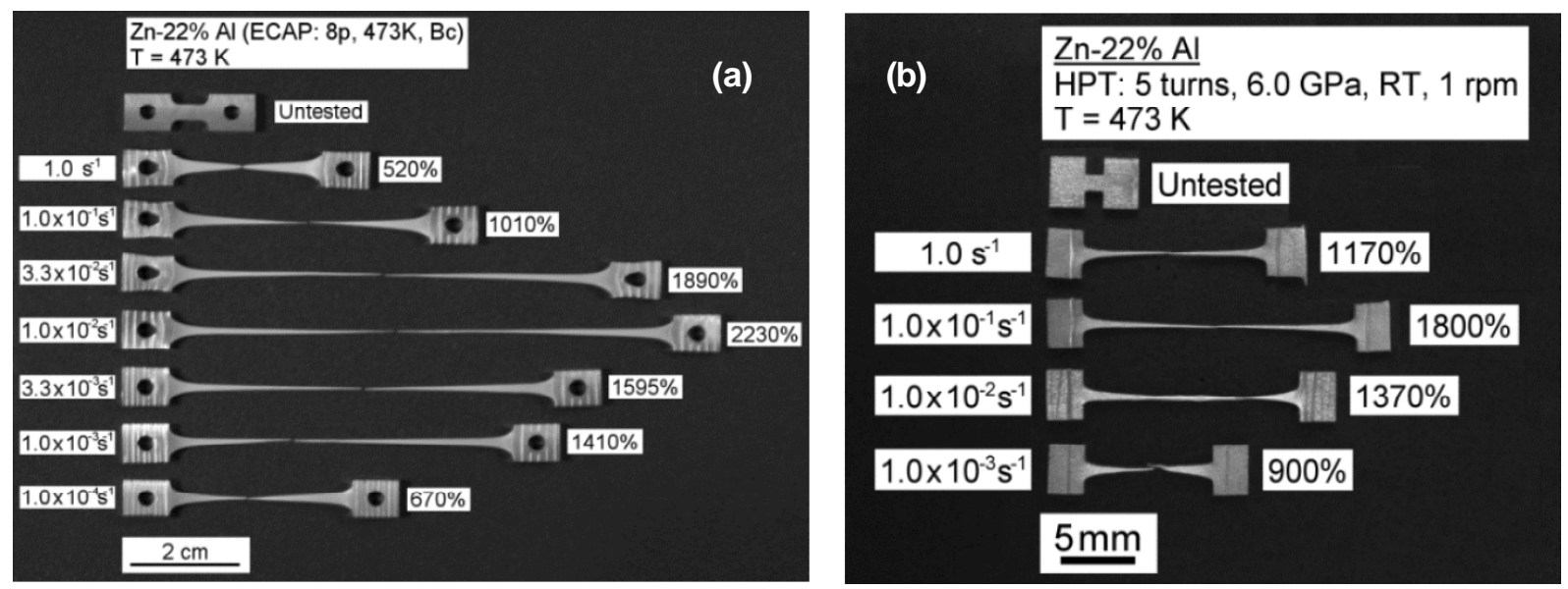

Fig. 3. Superplastic flow at different strain rates at $47 \mathrm{~K}$ in a $\mathrm{Zn}-22 \% \mathrm{Al}$ alloy after processing by (a) ECAP [17] and (b) HPT [18].

of by high-pressure torsion (HPT) through large numbers of turns [16]. Accordingly, this section now reviews experimental results showing the potential for achieving excellent superplastic ductilities at high temperatures in a $\mathrm{Zn}-22 \% \mathrm{Al}$ eutectoid alloy processed by ECAP or HPT. The analysis is extended to the theoretical creep equations developed for coarse-grained metals in order to evaluate the dominant deformation mechanisms by applying an appropriate deformation mechanism map.

A Zn-22\% Al eutectoid alloy was processed by ECAP through 8 passes at 473K [17] and also by HPT for 5 turns at room temperature using an applied pressure of $6.0 \mathrm{GPa}$ and a rotation speed of 1 rpm [18]. The initial grain size of $\sim 1.8-2.0 \mu \mathrm{m}$ was refined to $d \approx 1.5 \mu \mathrm{m}$ and $\sim 610 \mathrm{~nm}$ after ECAP and $\mathrm{HPT}$, respectively. Excellent superplastic ductilities were observed when tensile testing at $473 \mathrm{~K}$ for both samples over a range of strain rates of $10^{-4}-1.0 \mathrm{~s}^{-}$ ${ }^{1}$ for the samples after ECAP and $10^{-3}-1.0 \mathrm{~s}^{-1}$ for the samples after HPT. Figure 3 shows the tensile samples after deformation to failure for (a) the ECAPprocessed alloy [17] and (b) the HPT-processed alloy [18].

Exceptionally high elongations of $>1500 \%$ were recorded in both the ECAP and HPT-processed alloy and the maximum recorded elongations were $\sim 2230 \%$ at an initial strain rate of $1.0 \times 10^{-2} \mathrm{~s}^{-1}$ for the sample after ECAP and $\sim 1800 \%$ at an initial strain rate of $1.0 \times 10^{-1} \mathrm{~s}^{-1}$ for the sample after HPT. Although a direct comparison is not appropriate due to the different initial testing dimensions [19], the Zn-Al alloy after SPD processing demonstrated excellent superplasticity and the optimal strain rates are faster than $10^{-2} \mathrm{~s}^{-1}$ which correspond to the occurrence of high strain rate superplasticity [20].
The results in Fig. 3 show three important points for superplastic flow. First, the observed superplastic ductilities in the SPD-processed materials are consistent with the earlier demonstration that superplastic flow occurs over about two orders of magnitude of strain rate under conditions designated region II and there are reductions in the elongations to failure at both slower and faster strain rates in regions I and III [6]. Second, under optimum superplastic conditions the gauge lengths of the samples are pulled without exhibiting any necking within the gauge length where this is a basic requirement for superplastic flow [21]. Third, the maximum elongation of $\sim 1800 \%$ occurs at a faster strain rate after HPT processing than after ECAP processing and this is due to the smaller grain size in the HPT samples since a reduction in grain size displaces the optimum ductility to faster strain rates [22].

The experimental data from the tensile testing were evaluated by constructing a deformation mechanisms map using the format of $d / \mathbf{b}$ against $\sigma / G$ at a constant testing temperature of $473 \mathrm{~K}$ and the result is shown in Fig. 4 [18]. In practice, this map was computed for a testing temperature of 473K where regions I, II, and III denote the three regions of plastic flow associated with the $\mathrm{Zn}-22 \%$ Al alloy tested in an annealed condition without SPD processing [6] and the fields for Nabarro-Herring and Coble diffusion creep are based on the theoretical models [23-25]. A dashed line in the map shows the relationship of $d / \mathbf{b}=20(\sigma / G)^{-1}$ which defines experimentally that subgrains are formed under experimental testing conditions above the dashed line, thereby showing a reasonable agreement with the 


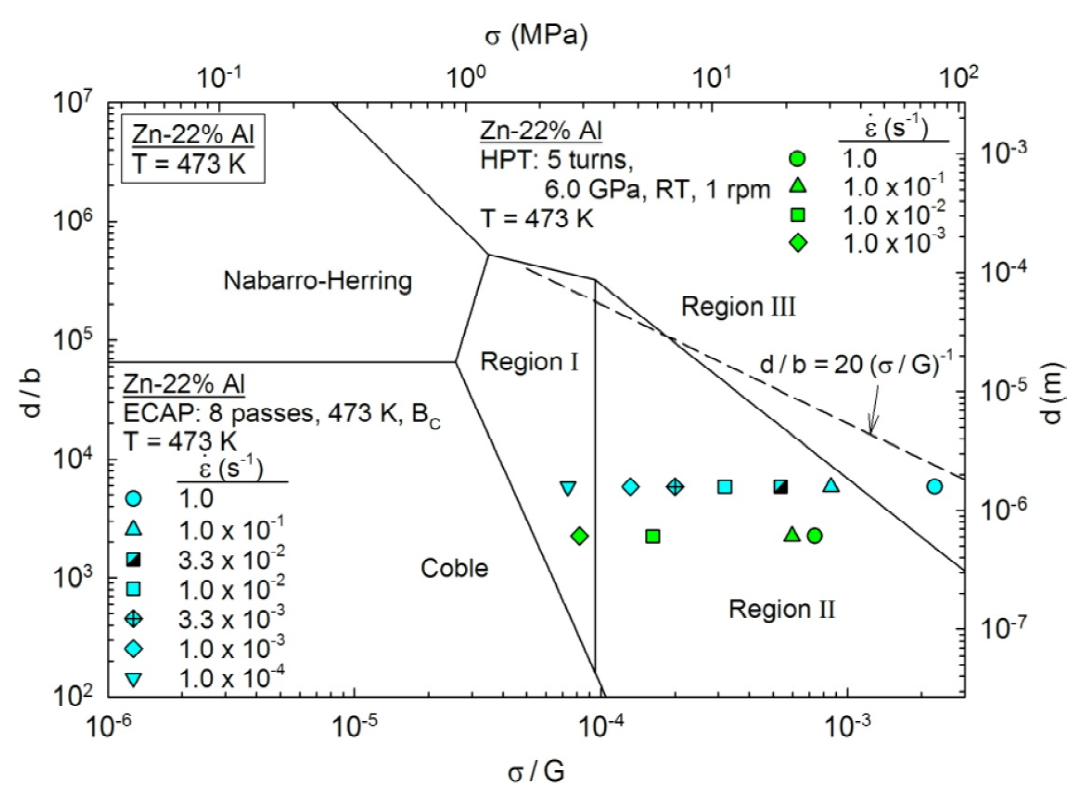

Fig. 4. A deformation mechanism map of normalized grain size versus normalized stress for a $\mathrm{Zn}-22 \% \mathrm{Al}$ alloy tested at $473 \mathrm{~K}$ [18]: experimental points are shown after processing by ECAP [17] and HPT [18].

field boundary between the superplastic region II and the non-superplastic region III.

The datum points for the ECAP and HPT samples are superimposed onto the map in Fig. 4. The datum points corresponding to the samples with excellent superplastic ductilities at intermediate strain rates lie within the superplastic region II for both the ECAP and HPT-processed samples. By contrast, the datum points falling outside of region II are for the specimens tested at the slowest strain rates for both the ECAP and HPT specimens and the fastest strain rate for the ECAP sample where these samples failed to exhibit real superplasticity without necking within the deformed gauge lengths as is evident by inspection of Figs. $3 a$ and $3 \mathrm{~b}$. Thus, the results demonstrate that the superplastic flow behavior of the $\mathrm{Zn}-22 \% \mathrm{Al}$ alloy processed by both ECAP and HPT is in excellent agreement with the deformation mechanism map based on the theoretical relationship describing the rate of flow. The same approach was used successfully in constructing similar deformation mechanism maps for a UFG $\mathrm{Pb}-62 \% \mathrm{Sn}$ eutectic alloy after ECAP for 4-16 passes and testing at $413 \mathrm{~K}$ [26] and at $423 \mathrm{~K}$ [27] and for a UFG Al-33\% Cu eutectic alloy after HPT for 10 turns at $6.0 \mathrm{GPa}$ and testing at $723 \mathrm{~K}$ [28].

\section{FLOW MECHANISMS IN ULTRAFINE-GRAINED MATERIALS}

The UFG metals prepared using SPD techniques provide excellent samples for achieving superplastic behavior and comparing the rates of flow with the theoretical model developed for regular superplastic metals having grain sizes of the order of a few micrometers. The basic flow relationship for GBS in superplasticity was given earlier in Eq. (1) where $Q=Q_{g b}, n=2, p=2$, and $A \approx 10$ [15]. It follows from Eq. (1) that it is possible to make a direct comparison with the theoretical model by plotting, on logarithmic axes, the temperature and grain size compensated strain rate, $\dot{\varepsilon} k T / D_{\mathrm{gb}} G \mathbf{b}(d / \mathbf{b})^{2}$, against the normalized stress, $\sigma / G$ [29].

An example is shown in Fig. 5 where all published data are collected together for a range of aluminum-based alloys processed initially to give UFG microstructures using either ECAP [30-39] or HPT [28,40-47]. All points scatter about the same general area within the strain rate-stress diagram and the upper solid line labeled $\dot{\varepsilon}_{\mathrm{sp}}$ represents the theoretical prediction based on the model shown in Fig. $2 \mathrm{~b}$ and Eq. (1). The points marked in black in Fig. 5 are for the results from the ECAP specimens, the points in red are for the HPT samples and the encircling ovals are in blue for ECAP and pink for HPT. It is readily apparent that all points, for both ECAP and HPT, fall on or about the theoretical line and therefore the analysis shows that the superplastic behavior of the SPD-processed samples is essentially the same as the flow behavior in conventional superplastic metals not processed by SPD. In general, it is also apparent that the ECAP data tend to lie, on average, about one-half order of magnitude higher in strain rate than the HPT data 


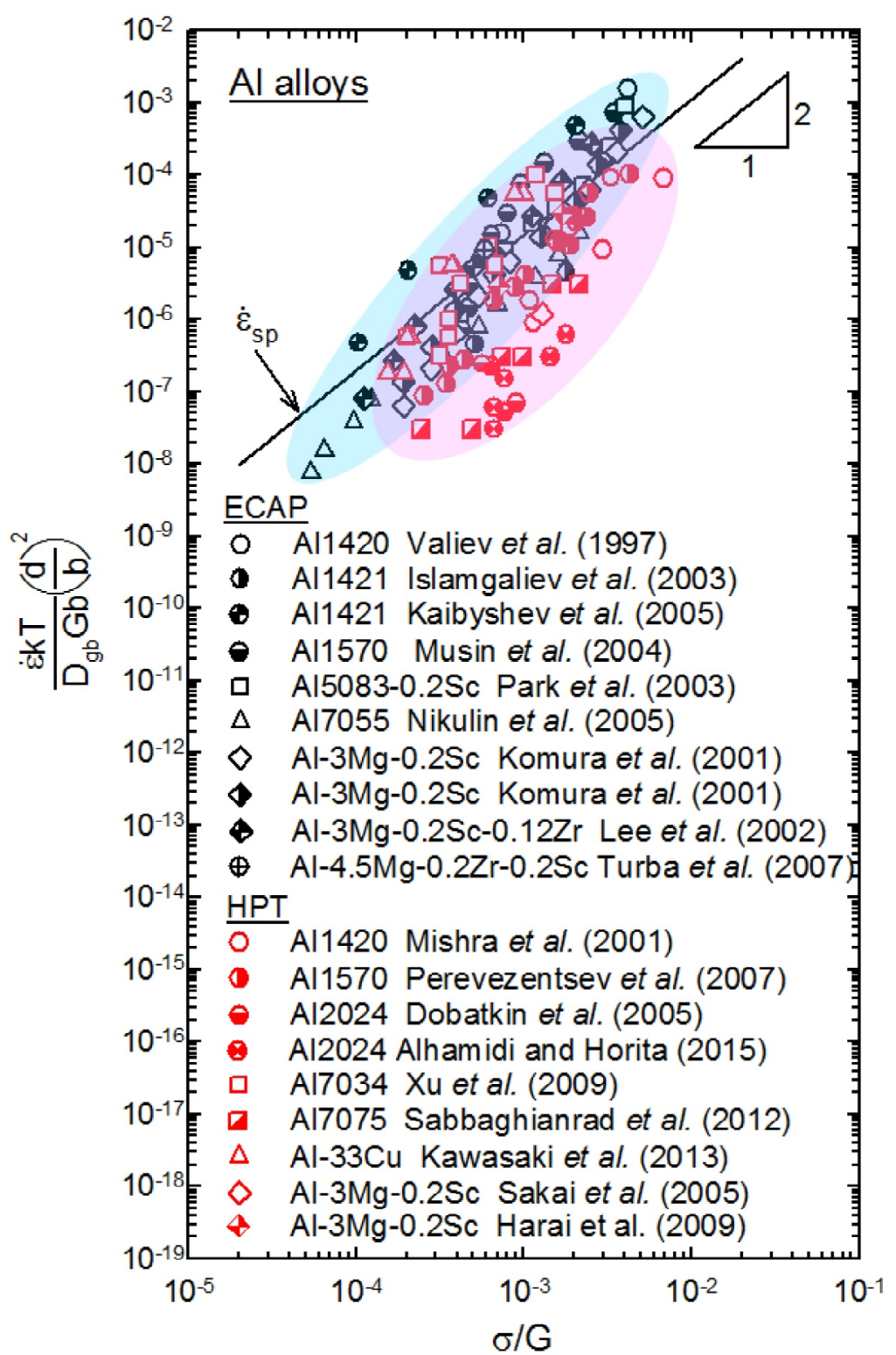

Fig. 5. A compilation of data for a series of UFG Al alloys [29] after ECAP [30-39] and HPT [28,40-47].

where this is due to the very small samples used for the HPT testing.

Fig. 6 shows a similar normalized plot for a large number of published reports for Mg alloys again using data for both ECAP [48-63] and HPT [64-67]. As with the Al alloys shown in Fig. 5, the datum points in Fig. 6 scatter about the line for the theoretical model and demonstrate again that there is excellent agreement with the predictions for conventional superplastic magnesium alloys. Thus, all available data for both $\mathrm{Al}$ and $\mathrm{Mg}$ alloys, based on results obtained from many different experiments, show a good general agreement with the standard model for the occurrence of GBS in superplasticity as illustrated schematically in Fig. $2 \mathrm{~b}$.

\section{RECENT DEVELOPMENTS IN THE CHARACTERIZATION OF MECHANICAL PROPERTIES OF UFG MATERIALS}

Recent advances in the processing of UFG metals have provided an opportunity to extend the understanding of superplastic flow behavior to include UFG materials with submicrometer grain sizes. In this section, in addition to evaluating superplasticity in UFG materials processed by SPD, a recent development in the understanding of plasticity in UFG metals is discussed in terms of the characterization techniques.

Mechanical properties are all structure-sensitive and these determine the response to the applica- 


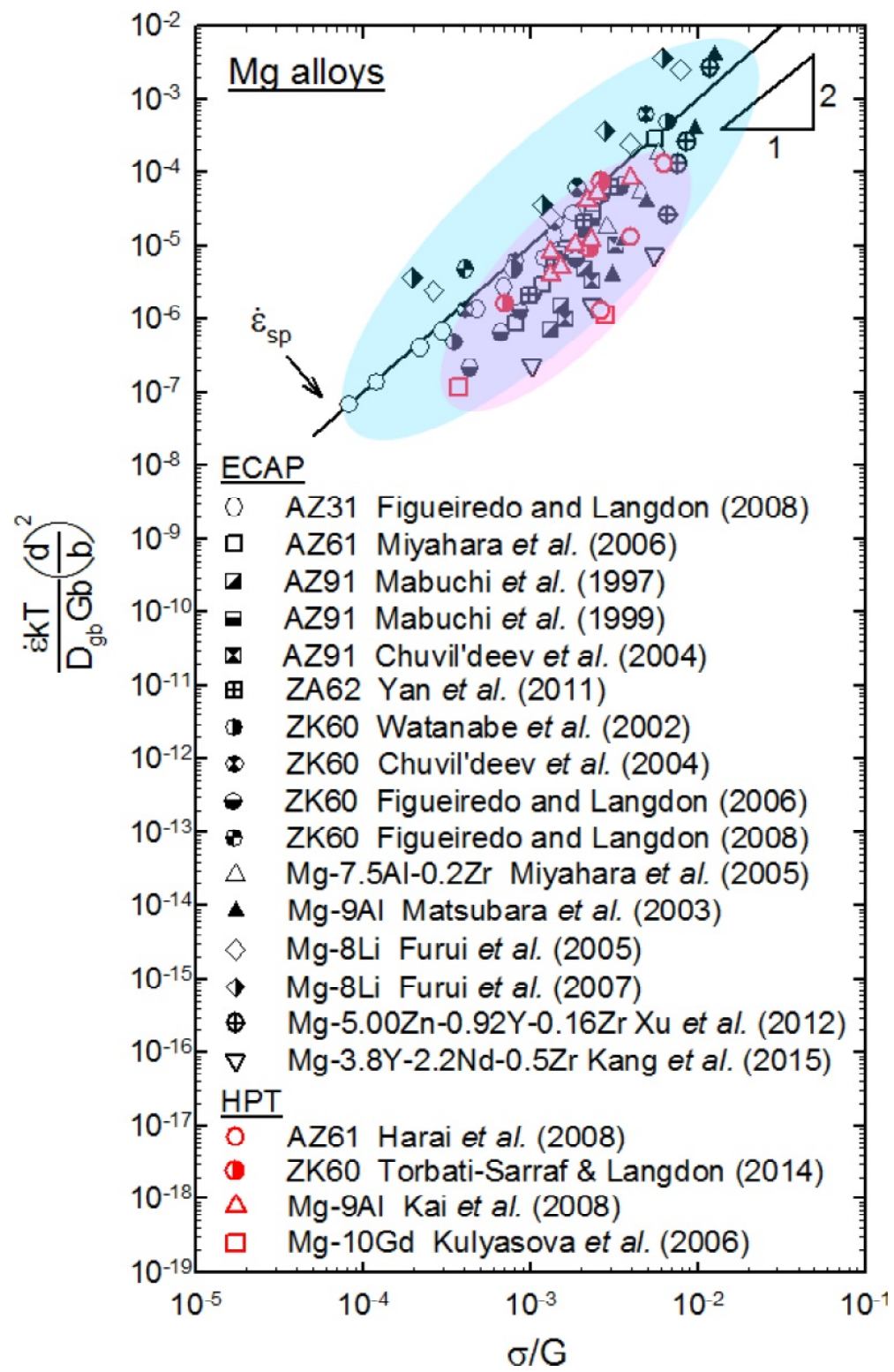

Fig. 6. A compilation of data for a series of Mg alloys [29] after ECAP [48-63] and HPT [64-67].

tion of a stress which is applied in tension, compression or shear and in a uniaxial or a combination mode. Studies of plastic deformation have been conducted for over 100 years by using specimens with stipulated gauge lengths in conventional tensile testing and this approach has been the main source for information on the mechanical properties of these materials. The values of stress and strain obtained from this testing procedure are considered as the immediate practical values of the mechanical properties of the material.

Nevertheless, there are several limitations in using the conventional tensile testing method and interpreting the testing results in the case of UFG materials processed by SPD. The most critical issue relates to the fact that the samples after SPD processing are too small to follow the testing standard leading to inevitable errors in the recorded mechanical properties. In practice, with the current interest in laboratory-scale studies on samples processed by SPD techniques, the tensile specimens machined from the SPD-processed materials have often failed to meet the geometry defined by the American Society for Testing and Materials (ASTM) standard [68].

Recent developments in characterization techniques now lead to a better understanding of the evolution, especially in the mechanical properties, of UFG materials processed by SPD. In particular, the novel technique of nanoindentation has become a common tool for the simultaneous measurement of a number of essential mechanical properties and 
the approach is advantageous because it requires only limited sample volumes. The use of the nanoindentation technique was reported to date for investigating the micro-mechanical properties of several SPD-processed metals including Al [69-73], $\mathrm{Cu}$ [74], $\mathrm{Cr}$ [75], Mg [76], Nb [77], Pb-62\%Sn eutectic [78] and Zn-22\%Al eutectoid [79] alloys, TiAl intermetallic compound [80], high entropy alloys [81,82], and metal-matrix nanocomposites [83].

The nanoindentation analysis permits an estimate of the strain rate sensitivity of materials and the relevant $m$ values estimated for these UFG materials after different SPD methods were summarized together with the measured strain rate sensitivities using regular tensile testing methods [84]. There are two important findings from this evaluation. First, the $m$ values are often improved or at least maintained consistent during grain refinement by SPD while the hardness and strength of the materials are enhanced significantly. Second, the estimated strain rate sensitivity values by different measurement methods show reasonable consistency except for the situation where a material shows a local anisotropic texture after SPD [71].

A characterization by nanoindentation is generally utilized for understanding the plastic yield on the nanoscale at the very early stage of deformation [85]. However, the technique is not adequate to determine the classical measures of overall ductility such as elongations to failure and uniform elongations under constant strain rates. Nevertheless, numerous practices have defined that measurements of the rate sensitivity are sufficient to permit a reasonably direct prediction of the stability of plastic deformation at elevated temperatures $[86,87]$. Moreover, an overall consideration of strain hardening and strain rate sensitivity is essential for understanding the plasticity and ductility of nanostructured materials at room temperature $[88,89]$. Thus, the results and information achieved by nanoindentation provide sufficient and valuable resources for evaluating the general mechanical properties in UFG materials processed by SPD.

\section{SUMMARY AND CONCLUSIONS}

1. The characteristics of superplastic metals are now well established. Superplasticity occurs over a limited range of strain rates in region $\mathrm{II}$ and the elongations to failure are reduced at both lower strain rates in region I and higher strain rates in region II. 2. Superplasticity occurs through grain boundary sliding which is accommodated by intragranular slip within the grains. A theoretical model is available to describe the occurrence of sliding under both conventional creep conditions where the grain sizes are very large and in superplastic materials where the grain sizes are typically less than $\sim 10 \mu \mathrm{m}$.

3. Deformation mechanism mapping gives a simple tool for providing a visual display describing the ratecontrolling flow processes over a range of experimental conditions. An example of a map is presented for a superplastic Zn-22\% Al alloy.

4. Calculations show there is very good agreement with the predictions of the theoretical model for superplastic flow for a wide range of ultrafine-grained $\mathrm{Al}$ and $\mathrm{Mg}$ alloys.

5. The use of nanoindentation provides an important tool for recording the mechanical behavior of superplastic alloys when only very small amounts of material are available.

\section{ACKNOWLEDGEMENTS}

Preparation of this review was supported in part by the European Research Council under ERC Grant Agreement No. 267464-SPDMETALS (TGL).

\section{REFERENCES}

[1] T.G. Langdon, In: Superplasticity in Advanced Materials - ICSAM-91, ed. by S. Hori, M. Tokizane and N. Furushiro (Japan Society for Research on Superplasticity, Osaka, Japan, 1991), p. 3.

[2] C.E. Pearson // J. Inst. Metals 54 (1934) 111.

[3] E.E. Underwood // JOM 14(12) (1962) 914.

[4] W.A. Backofen, L.R. Turner and D.H. Avery // Trans. ASM 57 (1964) 980.

[5] A.J. Barnes // J. Mater. Eng. Perform. 16 (2007) 440.

[6] H. Ishikawa, F.A. Mohamed and T.G. Langdon // Phil. Mag. 32 (1975) 1269.

[7] Y. Ma and T.G. Langdon // Metall. Mater. Trans. A 25A (1994) 2309.

[8] T.G. Langdon // J. Mater. Sci. 44 (2009) 5998.

[9] T.G. Langdon // Metall. Trans. A 13A (1982) 689.

[10] T.G. Langdon // Mater. Sci. Eng. A 174 (1993) 25.

[11] L.K.L. Falk, P.R. Howell, G.L. Dunlop and T.G. Langdon // Acta Metall. 34 (1986) 1203.

[12] R.Z. Valiev and T.G. Langdon // Acta Metall. Mater. 41 (1993) 949.

[13] Y. Xun and F.A. Mohamed // Phil. Mag. 83 (2003) 2247.

[14] F.A. Mohamed and T.G. Langdon // Scr. Metall. 10 (1976) 759. 
[15] T.G. Langdon // Acta Metall. Mater. 42 (1994) 2437.

[16] R. Valiev // Nature Mater. 3 (2004) 511.

[17] M. Kawasaki and T.G. Langdon // Mater. Trans. 49 (2008) 84.

[18] M. Kawasaki and T.G. Langdon // Mater. Sci. Eng. A 528 (2011) 6140.

[19] Y.H. Zhao, Y.Z. Guo, Q. Wei, A.M. Dangelewicz, C. Xu, Y.T. Zhu, T.G. Langdon, Y.Z. Zhou and E. Lavernia // Scr. Mater. 59 (2008) 627.

[20] K. Higashi, M. Mabuchi and T.G. Langdon // ISIJ Intl. 36 (1996) 1423.

[21] T.G. Langdon // Metal Sci. 16 (1982) 175.

[22] Y. Ma, M. Furukawa, Z. Horita, M. Nemoto, R.Z. Valiev and T.G. Langdon // Mater. Trans. JIM. 37 (1996) 336.

[23] F.R.N. Nabarro, In: Proceedings of the Conference on Strength of Solids (The Physical Society, 1948), p. 75.

[24] C. Herring // J. Appl. Phys. 21 (1950) 437.

[25] R.L. Coble // J. Appl. Phys. 34 (1963) 1679.

[26] M. Kawasaki, S. Lee and T.G. Langdon // Scr. Mater. 61 (2009) 963.

[27] M. Kawasaki, A.A. Mendes, V.L. Sordi, M. Ferrante and T.G. Langdon // J. Mater. Sci. 46 (2011) 155.

[28] M. Kawasaki, J. Foissey and T.G. Langdon // Mater. Sci. Eng. A 561 (2013) 118.

[29] M. Kawasaki and T.G. Langdon // J. Mater. Sci. 51 (2016) 19.

[30] R.Z. Valiev, D.A. Salimonenko, N.K. Tsenev, P.B. Berbon and T.G. Langdon // Scr. Mater. 37 (1997) 1945.

[31] R.K. Islamgaliev, N.F. Yunusova, R.Z. Valiev, N.K. Tsenev, V.N. Perevezentsev and T.G. Langdon // Scr. Mater. 49 (2003) 467.

[32] R. Kaibyshev, K. Shipilova, F. Musin and Y. Motohashi // Mater. Sci. Tech. 21 (2005) 408.

[33] F. Musin, R. Kaibyshev, Y. Motohashi and G. Itoh // Metall. Mater. Trans. A 35A (2004) 2383.

[34] K.T. Park, D.Y. Hwang, Y.K. Lee, Y.K. Kim and D.H. Shin // Mater. Sci. Eng. A 341 (2003) 273.

[35] I. Nikulin, R. Kaibyshev and T. Sakai // Mater. Sci. Eng. A 407 (2005) 62.

[36] S. Komura, M. Furukawa, Z. Horita, M. Nemoto and T.G. Langdon // Mater. Sci. Eng. A 297 (2001) 111.

[37] S. Komura, Z. Horita, M. Furukawa, M. Nemoto and T.G. Langdon // Metall. Mater. Trans. A 32A (2001) 707.
[38] S. Lee, A. Utsunomiya, H. Akamatsu, K. Neishi, M. Furukawa, Z. Horita and T.G. Langdon // Acta Mater. 50 (2005) 553.

[39] K. Turba, P. Málek and M. Cieslar // Mater. Sci. Eng. A 462 (2007) 91.

[40] R.S. Mishra, R.Z. Valiev, S.X. McFadden, R.K. Islamgaliev and A.K. Mukherjee // Phil. Mag. A 81 (2001) 37.

[41] V.N. Perevezentsev, M.Yu. Shcherban, M.Yu. Murashkin and R.Z. Valiev // Tech. Phys. Lett. 33 (2007) 648.

[42] S.V. Dobatkin, E.N. Bastarache, G. Sakai, T. Fujita, Z. Horita and T.G. Langdon // Mater. Sci. Eng. A 408 (2005)141.

[43] A. Alhamidi and Z. Horita // Mater. Sci. Eng. A 622 (2015) 139.

[44] C. Xu, S.V. Dobatkin, Z. Horita and T.G. Langdon // Mater. Sci. Eng. A 500 (2009) 170.

[45] S. Sabbaghianrad, M. Kawasaki and T.G. Langdon // J. Mater. Sci. 47 (2012) 7789.

[46] G. Sakai, Z. Horita and T.G. Langdon // Mater. Sci. Eng. A 393 (2005) 344.

[47] Y. Harai, K. Edalati, Z. Horita and T.G. Langdon // Acta Mater. 57 (2009) 1147.

[48] R.B. Figueiredo and T.G. Langdon // J. Mater. Sci. 43 (2008) 7366.

[49] Y. Miyahara, K. Matsubara, Z. Horita and T.G. Langdon // Metall. Mater. Trans. A 36A (2005) 1705.

[50] M. Mabuchi, H. Iwasaki, K. Yanase and K. Higashi // Scr. Mater. 36 (1997) 681.

[51] M. Mabuchi, K. Ameyama, H. Iwasaki and K. Higashi // Acta Mater. 47 (1999) 2047.

[52] V.N. Chuvil'deev, T.G. Nieh, M.Yu. Gryaznov, V.I. Kopylov and A.N. Sysoev // J. Alloys Compd. 378 (2004) 253.

[53] K. Yan, Y.-S. Sun, J. Bai and F. Xue // Mater. Sci. Eng. A 528 (2011) 1149.

[54] H. Watanabe, T. Mukai, K. Ishikawa and K. Higashi // Scr. Mater. 46 (2002) 851.

[55] V.N. Chuvil'deev, T.G. Nieh, M. Yu. Gryaznov, A.N. Sysoev and V.I. Kopylov // Scr. Mater. 50 (2004) 861.

[56] R.B. Figueiredo and T.G. Langdon // Mater. Sci. Eng. A 430 (2006) 151.

[57] R.B. Figueiredo and T.G. Langdon // $A d v$. Eng. Mater. 10 (2008) 37.

[58] Y. Miyahara, Z. Horita and T.G. Langdon // Mater. Sci. Eng. A 420 (2006) 240.

[59] K. Matsubara, Y. Miyahara, Z. Horita and T.G. Langdon // Acta Mater. 51 (2003) 3073. 
[60] M. Furui, C. Xu, T. Aida, M. Inoue, H. Anada and T.G. Langdon // Mater. Sci. Eng. A 410411 (2005) 439.

[61] M. Furui, H. Kitamura, H. Anada and T.G. Langdon // Acta Mater. 55 (2007) 1083.

[62] S.W. Xu, M.Y. Zheng, S. Kamado and K. Wu // Mater. Sci. Eng. A 549 (2012) 60.

[63] Z. Kang, L. Zhu and J. Zhang // Mater. Sci. Eng. A 633 (2015) 59.

[64] Y. Harai, M. Kai, K. Kaneko, Z. Horita and T.G. Langdon // Mater. Trans. 49 (2008) 76.

[65] S.A. Torbati-Sarraf and T.G. Langdon // J. Alloys Compd. 613 (2014) 357.

[66] M. Kai, Z. Horita and T.G. Langdon // Mater. Sci. Eng. A 488 (2008) 117.

[67] O.B. Kulyasova, R.K. Islamgaliev, A.R. Kil'mametov and R.Z. Valiev // Phys. Met. Metallogr. 101 (2006) 585.

[68] ASTM http://www.astm.org

[69] J. Mueller, K. Durst, D. Amberger and M. Göken // Mater. Sci. Forum 503-504 (2006) 31.

[70] V. Maier, K. Durst, J. Mueller, B. Backes, H.W. Höppel and M. Göken // J. Mater. Res. 26 (2011) 1421.

[71] A. Böhner, V. Maier, K. Durst, H.W. Höppel and M. Göken // Adv. Eng. Mater. 13 (2011) 251.

[72] V. Maier, B. Merle, M. Göken and K. Durst // J. Mater. Res. 28 (2013) 1177.

[73] J.M. Wheeler, V. Maier, K. Durst, M. Göken and J. Michler // Mater. Sci. Eng. A 585 (2013) 108.

[74] J. Chen, L. Lu and K. Lu // Scr. Mater. 54 (2006) 1913.

[75] V. Maier, A. Hohenwarter, R. Pippan and D. Kiener // Scr. Mater. 106 (2015) 42.
[76] I.-C. Choi, D.-H. Lee, B. Ahn, K. Durst, M. Kawasaki, T.G. Langdon and J.-I. Jang // Scr. Mater. 94 (2015) 44.

[77] J. Alkorta, J.M Martínez-Esnaola and J.G. Sevillano // Acta Mater. 56 (2008) 884.

[78] N.X. Zhang, N.Q. Chinh, M. Kawasaki, Y. Huang and T.G. Langdon // Mater. Sci. Eng. A 666 (2016) 350.

[79] I.-C. Choi, Y.-J. Kim, B. Ahn, M. Kawasaki, T.G. Langdon and J.-I. Jang // Scr. Mater. 75 (2014) 102.

[80] J.-K. Han, X. Li, R. Dippenaar, K.-D. Liss and M. Kawasaki // Mater. Sci. Eng. A 714 (2018) 84.

[81] D.-H. Lee, I.-C. Choi, M.-Y. Seok, J. He, Z. Lu, J.-Y. Suh, M. Kawasaki, T.G. Langdon and J.-I. Jang // J. Mater. Res. 30 (2015) 2804.

[82] D.-H. Lee, J.-A. Lee, Y. Zhao, Z. Lu, J.-Y. Suh, J.-Y. Kim, U. Ramamurty, M. Kawasaki, T.G. Langdon and J.-I. Jang // Acta Mater. 140 (2017) 443.

[83] J.-K. Han, H.-J. Lee, J.-i. Jang, M. Kawasaki and T.G. Langdon // Mater. Sci. Eng. A 684 (2017) 318.

[84] M. Kawasaki, B. Ahn, P. Kumar, J.-i. Jang and T.G. Langdon // Adv. Eng. Mater. 19 (2017) 1600578.

[85] C.A. Schuh // Mater. Today 9 (2006) 32.

[86] D.A. Woodford // Trans. ASM 62 (1969) 291.

[87] T.G. Langdon // Scr. Metall. 11 (1977) 997.

[88] Y.M. Wang and E. Ma // Mater. Sci. Eng. A 375-377 (2004) 46.

[89] T. Zhu, J. Li, A. Samanta, H.G. Kim and S. Suresh // PNAS 104 (2007) 3031. 